\section{QUALITY OF LIFE PADA LANSIA}

\author{
Quality of Life in The Elderly
}

\section{Lina Ekawati' ${ }^{1}$, Chilyatiz Zahroh ${ }^{1 *}$, Annif Munjidah ${ }^{1}$, Wiwik Afridah ${ }^{2}$, Iis Noventi ${ }^{1}$, Priyo Mukti Pribadi Winoto ${ }^{1}$}

1. Magister Keperawatan, Faculty of Nursing, Universitas Indonesia

2. Universitas Nahdatul Ulama Surabaya

\section{Riwayat artikel \\ Diajukan: \\ 23 September 2020 \\ Diterima:}

25 September 2020

\section{Penulis Korespondensi:}

- Chilyatiz Zahroh

- Fakutlas Keperawatan dan Kebidanan Universitas Nahdlatul Ulama Surabaya

- chilyatiz@unusa.ac.id

\section{Kata Kunci:}

lansia, quality of life

\section{Abstrak}

Pendahuluan : Kualitas hidup adalah persepsi seseorang/individu terhadap kehidupan dalam masyarakat berdasar konteks budaya serta sistem nilai yang sesuai dengan tujuan, standar atau norma, dan perhatian. Tujuan: Tujuan penelitian ini untuk mengetahui kualitas hidup pada Lansia di Desa Paseseh Jl. Melati Kecamatan Tanjung Bumi Kabupaten Bangkalan. Metode: Desain penelitian yang digunakan adalah deskriptif. Populasi penelitian ini adalah lansia di Desa Paseseh Jl. Melati Kecamatan Tanjung Bumi Kabupaten Bangkalan sebesar 32 orang, dengan total sampling maka besar sampel adalah 32 responden. Variabel yang digunakan dalam penelitian ini adalah variabel tunggal yaitu Quality of Life Yang diukur menggunakan kuesioner dari Word Health Organization Quality Of Life (WHQOL)-BREF. Data yang didapat dianalisis dan disajikan dalam bentuk dan dijelaskan secara deskriptif. Hasil: Hasil penelitian ini menunjukkan bahwa Lansia di Desa Pasese Bangkalan 53.2\% memiliki kualitas hidup baik, 28.1\% kualitas hidup biasa-biasa saja, $15.6 \%$ sangat baik, dan $3.1 \%$ buruk.. Kesimpulan: Upaya untuk meningkatkan quality of life pada lansia dengan memberikan perhatian dan perawatan yang baik sehingga lansia hidup dalam keadaan sehat, aktif serta menikmati masa tua dengan bahagia.

\section{Abstract}

Background: Problem. Quality of life is an individual's perception of his or her life in society in the context of existing cultures and value systems related to goals, standards, and concerns. Objective The purpose of this research is to find out the quality of life in the Elderly. Method: The research design used was descriptive. The population of this study was elderly in Paseseh Village Jl. Melati Tanjung Bumi District Bangkalan Regency which numbered 32 people. Sampling technique was used non probability sampling with total sampling technique where the number of samples is equal to the number of populations. The variable used in this study was a single variable, Quality of Life, which was measured using a questionnaire from word health organization Quality Of Life (WHQOL)-BREF. Data analysis were presented in the frequency distribution table and described descriptively. Results: The results showed that elderly in Pasese Bangkalan Village $53.2 \%$ have good quality of life, $28.1 \%$ mediocre quality of life, $15.6 \%$ very good, and $3.1 \% \mathrm{bad}$. Conclusion: Efforts to improve the quality of life in the elderly by providing good care and attention so that the elderly live in a healthy, active state and enjoy the old age happily. 


\section{PENDAHULUAN}

Kualitas hidup adalah persepsi seseorang/individu terhadap kehidupannya dimasyarakat dalam konteks budaya dan sistem nilai yang ada terkait dengan tujuan, standar, dan perhatian. Kualitas hidup merupakan suatu konsep yang sangat luas yang dipengaruhi kondisi fisik, psikologis, tingkat kemandirian atau sosial dan hubungan individu dengan lingkungan (Puspadewi, 2017). Sehingga dimensi dalam kualitas hidup meliputi : dimensi kesehatan fisik, psikologis, social dan lingkungan. Namun hal tersebut belum pernah diteliti di Desa Pasese Bangkalan.

Dalam waktu hampir lima decade (dua puluh tahun), jumlah persentase lansia Indonesia meningkat dua kali lipat (1971-2019), yakni menjadi 9,6 persen (25juta-an) di mana lansia perempuan sekitar satu persen lebih banyak dibandingkan lansia laki-laki (10,10persen banding 9,10 persen). Dari seluruh lansia yang ada di Indonesia, lansia muda(60-69 tahun)jauh mendominasi dengan besaran yang mencapai 63,82 persen, selanjutnya diikuti oleh lansia madya(70-79 tahun)dan lansia tua(80+ tahun) dengan besaran masing-masing 27,68 persen dan 8,50persen. Pada tahun ini sudah ada lima provinsi yang memiliki struktur penduduk tua dimana penduduk lansianya sudah mencapai 10 persen, yaitu: DI Yogyakarta (14,50persen), Jawa Tengah (13,36 persen), Jawa Timur (12,96persen), Bali (11,30 persen) dan Sulawesi Barat (11,15 persen) (Kementerian Kesehatan RI, 2018). Sedangkan di Bangkalan pada tahun 2016 terdapat 103.458 lansia (Badan Pusat Statistik Kabupaten Bangkalan, 2017). Data Awal yang didapatkan pada 19 Juni 2020 di Desa Paseseh Jl. Melati Tanjung Bumi Bangkalan, bahwa jumlah lansia yang ada di desa Paseseh Jl. Melati tersebut sebanyak 32 lansia terbagi menjadi 12 laki-laki dan 20 perempuan.

Peningkatan jumlah penduduk lansia ini akan membawa dampak terhadap berbagai sector kehidupan. Dampak utama peningkatan lansia ini adalah peningkatan ketergantungan lansia dan angka kesakitan lansia juga meningkat. Kondisi ini dapat menyebabkan morbiditas bagi para lanjut usia jika tidak tertangani dengan baik, dapat menyebabkan dampak buruk bagi kualitas hidup lanjut usia yang berujung pada meningkatnya angka kesakitan dan kematian. Adaptasi terhadap proses penuaan sangatlah diperlukan sehingga lansia tetap dapat mempertahankan kualitas hidup, banyak faktor yang harus dijadikan fokus perhatian karena dalam menentukan kualiatas hidup lansia tidaklah dapat berdiri sendiri (Wikananda, 2017).

Upaya yang dapat dilakukan terhadap quality of life pada lansia dengan memberikan perhatian dan perawatan yang baik sehingga lansia hidup dalam keadaan tetap sehat, aktif serta menikmati masa tua dengan bahagia, dan meningkatkan kualitas hidup lansia (Azwan, 2015).

Berdasarkan latar belakang tersebut peneliti ingin mengetahui Quality Of Life pada Lansia di Desa Paseseh Jl. Melati Kecamatan Tanjung Bumi Kabupaten Bangkalan.

\section{METODE}

Jenis penelitian ini adalah penelitian deskriptif yang menggambarkan kualitas hidup lansia yang tinggal di Desa Paseseh Jl. Melati Tanjung Bumi Bangkalan. Jumlah penduduk lansia di wilayah ini sebanyak 32 orang, dengan total sampling maka jumlah sample pada penelitian ini sama dengan besar populasi, yaitu 32 responden. Variabel yang diukur dalam penelitian ini adalah kualitas hidup lansia. Data didapatkan denga menggunakan kuisioner kualitas hidup dari WHO. Data yang didapatkan dianalisis dalam bentuk table dan dinarasikan.

Calon responden sebelumnya diberi penjelasan mengenai tujuan penelitian ini, jika responden setuju maka responden menandatangani surat persetujuan responden. Selanjutnya responden diberi kuioner kualitas hidup untuk diisi dengan lengkap.

Kuisioner yang telah dikembalikan oleh responden selanjutnya dicek dan direkapitulasi untuk dianalisis.

Penelitian ini telah dinyatakan laik etik oleh Komisi Etik Penelitian Kesehatan (KEPK) Universitas Nahdlatul Ulama Surabaya (Unusa) dengan SK No. 182/EC/KEPK/UNUSA/2020.

\section{HASIL DAN PEMBAHASAN HASIL PENELITIAN}

Tabel 1. Data Karakteristik Responden

\begin{tabular}{lcc}
\hline Characteristics & $\mathrm{N}(\mathrm{n}=32)$ & $\%$ \\
\hline Usia & & \\
$60-74$ & 20 & 62,5 \\
$75-90$ & 12 & 37,5 \\
\hline Jenis Kelamin & & \\
Male & 12 & 37,5 \\
Female & 20 & 62,5 \\
\hline Education & & \\
$\quad$ Tidak sekolah & 14 & 43,75 \\
$\quad$ Pendidikan & 18 & 56,25 \\
Dasar & & \\
\hline
\end{tabular}


Table 2. Distribusi Frekuensi Kualitas Hidup Lansia

\begin{tabular}{cccc}
\hline No & Kualitas Hidup & Frekuensi (N) & Presentase (\%) \\
\hline 1 & Sangat buruk & 0 & $0 \%$ \\
\hline 2 & Buruk & 1 & $3,1 \%$ \\
3 & Biasa-biasa saja & 9 & $28,1 \%$ \\
\hline 4 & Baik & 17 & $53,2 \%$ \\
\hline 5 & Sangat baik & 5 & $15,6 \%$ \\
\hline & Total & 32 & $100 \%$ \\
\hline
\end{tabular}

\section{PEMBAHASAN}

Kualitas hidup berdasarkan WHO terdiri dari empat domain yaitu kesehatan fisik, psikologis, domain sosial, dan domain lingkungan. Ke empat domain kulaitas hidup diidentifikasikan sebagai suatu perilaku atau tindakan, status, keberadaan, kapasitas, potensial, dan persepsi serta pengalaman subjektif (Meilani, 2015).

Domain kesehatan fisik berdasarkan kondisi fisik yang semakin rentan membuat lanjut usia merasa kehidupannya sudah tidak berarti lagi dan putus asa dengan kehidupan yang dijalani sekarang ini. Ini menjadi salah satu tanda rendahnya kualitas hidup lanjut usia dikarenakan lansia tidak bisa menikmati masa tuanya. Oleh karena itu, pelayanan kesehatan bagi penduduk lansia sangat menuntut perhatian, agar lansia dapat menghabiskan sisa usia dengan optimal (Anggun, 2018). Kondisi fisiologis lansia mengalami penurunan pada sebagian atau bahkan seluruh kemampuan tubuh, hal tersebut secara normal melalui proses penuaan akan mempengaruhi aktivitas sehari-hari (Anggraini, 2013). Proses penuan yang menyebabkan lansia rentan terhadap masalah kesehatan. Upaya perawat melalui komunikasi terapeutik dapat meningakatkan imunitas (Zahroh, 2020). Perawat dapat memberikan komunikasi terapeutik baik secara verbal maupun nonverbal, sehingga lansia menjadi relaks, hormone kortisol menurun dalam batas normal dan menjadikan lansia tidak mudah sakit.

Kesejahteraan psikologis menjadi salah satu faktor atau domain yang menentukan kualitas hidup lansia. Faktor psikologis merupakan faktor penting bagi individu untuk melakukan kontrol terhadap semua kejadian yang dialaminya dalam hidup. Perubahan psikologis berasal dari kesadaran tentang merosotnya dan perasaan rendah diri apabila dibandingkan dengan orang yang lebih muda, kekuatan, kecepatan, dan keterampilan. Aspek psikologi juga terkait dengan aspek fisik, dimana individu dapat melakukan suatu aktivitas jika individu itu sehat secara mental. Pada penelitian yang dilakukan oleh (Santoso, 2019) mengungkapkan gangguan mental akan menimbulkan gangguan dalam hal vitalitas hidup, fungsi sosial, keadaan emosional dan kesehatan mental secara umum. Jika seseorang mampu mencapai kesejahteraan psikologis yang baik akan berpengaruh pada peningkatan kualitas hidupnya (Setiyorini, 2018). Kondisi psikologis dipengaruhi oleh persepsi. Persepsi pula akan mempengaruhi kesehatan (Zahroh, 2020).

Hasil penelitian menunjukkan hubungan yang bermakna antara faktor sosial dengan kualitas hidup lansia. Lansia yang aktif dalam aktivitas sosial, seperti tergabung dalam paguyuban lansia atau posyandu lansia, memiliki ruang atau kesempatan untuk saling bertukar pikiran, berbagi pengalaman dan saling memberikan perhatian. Kegiatan yang dilakukan oleh lanjut usia dapat memfasilitasi hubungan antara lanjut usia satu dengan lanjut usia lainnya sehingga terbentuk reaksi sosial yang baik di antara lanjut usia tersebut, yang pada akhirnya akan berpengaruh pada kualitas hidup mereka. Oleh karena itu, keaktifan lansia dalam aktivitas sosial akan berdampak pada peningkatan kualitas hidupnya (Setiyorini, 2018).

Lingkungan keadaan tempat tinggal individu dimana rumah merupakan struktur fisik atau bangunan untuk tempat berlindung. Lingkungan rumah mendukung untuk meningkatkan kesehatan jasmani dan rohani serta keadaan dalam menjalin hubungan yang baik untuk kesehatan keluarga atau individu. Kebanyakan responden melaporkan bahwa lingkungan rumah merupakan komponen penting dalam kesembuhan dan perbaikan kualitas hidup mereka kedepannya, karena di lingkungan rumah inilah mereka mendapat dukungan dari keluarga atau orang-orang terdekat. Menurut (Untari, 2018) mendefinisikan kualitas merupakan persepsi seseorang akan dirinya dalam konteks budaya dan norma atau aturan yang sesuai dengan tempat hidup seseorang yang berkaitan dengan tujuan dan standart kualitas hidup antara satu dan lainnya

\section{KESIMPULAN}

Quality of life berdasarkan kuisioner WHO meliputi domain kesehatan fisik, psikologis, hubungan sosial, dan lingkungan.

\section{DAFTAR PUSTAKA}

Anggraini, F.D. 2013. Hubungan Efek Samping Obat Anti Hipertensi dengan Kualitas Hidup Penderita Hipertensi di Poli 
Spesialis Penyakit Dalam Rs Islam Ahmad Yani Surabaya (Skripsi). Surabaya: Stikes Yarsis

Anggun. 2018. Hubungan Konsep Diri (Citra Dir) dengan Kualitas Hidup Pasien Kanker yang Menjalani Pengobatan di Yayasan Kanker Indonesia Cabang Jawa Timur Surabaya (Skripsi). Surabaya: Universitas Nahdlatul Ulama Surabaya

Azwan. dkk. Hubungan Dukungan Sosial Teman Sebaya Dengan Kualitas Hidup Lansia di Panti Sosial Tresna Werdha. JOM. Volume 2 No. 2 Oktober 2015. Riau: Universitas Riau

Kementerian Kesehatan Republik Indonesia. 2018. Riset Kesehatan Dasar. Jakarta: Kementerian Kesehatan Republim Indonesia

Meilani, F. 2015. Kualitas Hidup Pasien Penderita Penyakit Ginjal Kronik yang Menjalani Hemodialisasi (Jurnal Ners Vol 11 No. 11, Desember 2019). Surabaya: Fakultas Keperawatan Universitas Airlangga Surabaya

Pupadewi AAAR, Rekawati E. 2017. Depresi Berhubungan dengan Kualitas Hidup Lansia di Panti Sosial Tresna Werdha di Jakarta. Jurnal Keperawatan Indonesia Vol 20 N0 3

Santoso, Y.D.M. 2019. Dukungan Sosial Meningkatkan Kualitas Hidup Lansia. J.K Mesencephalon. Volume 5 Nomor 1 April 2019. Prijonegoro Sragen: RSUD dr. Soehadi

Setiyorini, E. 2018. Upaya Untuk Meningkatkan Kualitas Hidup Lansia Melalui Perlahat (Persatuan Lansia Ingin Hidup Sehat). Volume 2 Nomor 2 Desember 2018. Blitar: STIKes Patria Husada

Untari Ida. 2018. Buku Ajar Keperawatan Gerontik: Terapi Ajar Tertawa \& Senam Lansia (Quality Of Life Elderly). Jurnal Keperawatan. Volume 3, Nomor 2 Juli 2012. Malang: Fakultas Ilmu Kesehatan Universitas Muhammadiyah

Wikananda G. 2017. Hubungan kualitas hidup dan faktor resiko pada usia lanjutdi wilayah kerja puskesmas tampaksiring I Kabupaten Gianyar Bali 2015. Intisari Sain Medis, Vol 8, Number 1:41-49

Zahroh C, Khamida, Anggraini R, Yusuf A, , Sudiana IK. 2020. The Relationship of Intelligence and Health Perceptions. Indian Journal of Public Health Research \& Development 11 (5), 630-633
Zahroh C, Yusuf A, Sudiana IK, Putra ST. 2020. Effect of Nursing Terapeutic Communication (Spiritual Approach) Onperception, Cortisol and HSP70 Family Members with High Risk of TB Infection. Journal of Engineering and Applied Sciences 15 (1), 279-282 